\title{
Nanoscale
}

Received 00th January 20xx, Accepted 00th January 20xx

DOI: $10.1039 / x 0 x \times 00000 x$

www.rsc.org/

\section{Macroscopic Fibres of CNTs as Electrodes for Multifunctional Electric Double Layer Capacitors: from Quantum Capacitance to Device Performance}

\begin{abstract}
E. Senokos ${ }^{\mathrm{a}, \mathrm{b}}$, V. Reguero ${ }^{\mathrm{b}}$, J. Palma ${ }^{\mathrm{a}}$, J.J. Vilatela*b, Rebeca Marcilla*a
In this work we present a combined electrochemical and mechanical study of mesoporous electrodes based on CNT fibres in the context of electric double layer capacitors. We show that through control of the synthetic and assembly processes of the fibres, it is possible to obtain an active material that combines a surface area of $250 \mathrm{~m}^{2} / \mathrm{g}$, high electrical conductivity $\left(3.5 \times 10^{5} \mathrm{~s} / \mathrm{m}\right)$ and mechanical properties in the high-performance range including toughness $(35 \mathrm{~J} / \mathrm{g})$ comparable to that of aramid fibre (e.g. Kevlar). These properties are a consequence of the predominant orientation of the CNTs, observed by wide- and small-angle X-ray diffraction, and to the exceptionally long CNT length in the milimetre scale. Cyclic voltammetry measurements in three-electrode configuration and using 1-butyl-3-methylpyrrolidinium bis(trifluoromethylsulfonyl)imide (PYR 14 TFSI) ionic liquid electrolyte, show that the CNT fibres have a large quantum capacitance, evidenced by a near linear dependance of geometric capacitance (and conductivity) on potential bias. This reflects the low dimensionality of the CNT building blocks, which were purposely synthesised to have 1-5 layers and a high degree of graphitization. From charge-discharge measurements of supercapacitor devices with symmetric CNT fibre electrodes we obtain power and energy densities as high as $58 \mathrm{~kW} / \mathrm{kg}$ and $14 \mathrm{Wh} / \mathrm{kg}$, respectively. These record-high values for CNT fibre-based supercapacitors, are a consequence of a low equivalent series resistance due to high conductivity of the fibres, the large contribution from quantum capacitance, and the wide stability window of the ionic liquid (3.5 V). Long term experiments demonstrate stable capacitance and energy retention during 10000 cycles of chargedischarge at $3.5 \mathrm{~V}$
\end{abstract}

\section{Introduction}

Electrochemical energy storage devices, such as batteries and supercapacitors, are attracting evergrowing interest due to the increasing demand for energy storage systems able to be coupled to intermittent renewable energy sources, such as photovoltaic and wind energies (associated to the development of the smart grids); the electrification of the transport sector; and the drive for portable electronic devices with added features such as mechanical flexibility, resilience or the possibility of integration as textiles. ${ }^{1-3}$

Amongst energy storage devices, supercapacitors (SC), also known as ultracapacitors or electric double layer capacitors (EDLC), are particularly attractive because of their high power density and long cycle life. ${ }^{4}$ They have also a comparatively simpler construction and are less hazardous. The energy

\footnotetext{
a.IMDEA Energy Institute, Avda. Ramón de la Sagra 3, Móstoles, 28935, Madrid, Spain.

b. IMDEA Materials Institute, C/ Eric Kandel, 2, Getafe, 28906, Madrid, Spain.

+ Electronic Supplementary Information (ESI) available: See
} DOI: $10.1039 / x 0 x x 00000$ storage mechanism in EDLC relies on the formation of a double layer of charge at the electrolyte-electrode interface; thus benefiting from a large specific surface area of the active material. Most commercial EDLC comprise electrodes made up of activated carbon, typically produced by mixing carbonised coconut husk with carbon black and a polymer binder, with specific surface areas as high as $\mathrm{S}_{\mathrm{BET}} \sim 1500-2000 \mathrm{~m}^{2} / \mathrm{g}$ that result in specific capacitances in the range of $100-150 \mathrm{~F} / \mathrm{g} .{ }^{5-7}$ However, the interest in light-weight portable electronic devices that can be stretched, bent, woven, and in general withstand large strains/stresses, calls for tough, flexible and/or structural supercapacitors with a different class of active materials. ${ }^{8-11}$ At the high end of mechanical properties carbon fibres (CF), with strength of 3-7 GPa and modulus 200-965 $\mathrm{GPa}$, have been investigated as active material components that are simultaneously structural elements and energy storing devices. ${ }^{12}$ One of the main challenges to realise this groundbreaking concept is to increase the intrinsically low surface area of CFs $\left(0.2 \mathrm{~m}^{2} / \mathrm{g}\right)$ and the correspondingly low specific capacitance $(0.06 \mathrm{~F} / \mathrm{g}$ in $3 \mathrm{M} \mathrm{KCl}) .{ }^{12}$ Improvements in specific surface area and electrochemical properties of CFs by chemical activation with $\mathrm{KOH}\left(23 \mathrm{~m}^{2} / \mathrm{g}\right.$ and $\left.3.27 \mathrm{~F} / \mathrm{g}\right),{ }^{13}$ adding carbon nanotubes $\left(21 \mathrm{~m}^{2} / \mathrm{g}\right.$ and $\left.2.63 \mathrm{~F} / \mathrm{g}\right)$ or carbon aerogels 
(163 $\mathrm{m}^{2} / \mathrm{g}$ and $\left.14 \mathrm{~F} / \mathrm{g}\right)^{14}$ have been reported. However, power and energy densities of CFs-based structural supercapacitors remain in the low range of $1 \mathrm{~W} / \mathrm{Kg}$ and $1 \mathrm{mWh} / \mathrm{kg}$, respectively. ${ }^{15}$ On the other hand, by using bicontinuous polymer electrolytes, some of the composite structures exhibit impressive matrix-dominated mechanical properties, such as high shear modulus and high interfacial shear strength, both essential for composites aiming to replace structural components. ${ }^{16}$

Another strategy consists in replacing both the active material and current collector with a high surface area network of nanocarbons (CNTs or graphene) to carry out these functions while also having a low density and withstanding mechanical deformations unsuitable for traditional activated carbons. Often, this is achieved by depositing the nanocarbon onto a flexible substrate such as cellulose paper, ${ }^{17-19}$ plastic $^{20,21}$ or carbon cloths. ${ }^{22}$ Another possibility is produce self-standing allnanocarbon membranes by vacuum filtration. ${ }^{23,24}$ These membranes combine a capacitance in the range of 50-100 F/g and a large flexibility in bending, although mainly as a consequence of the small diameter (thickness) of the constituent nanocarbons and small thickness of the devices (bending stiffness scales with (radius) ${ }^{4}$ ). However, the relatively low aspect ratio of the nanocarbon (CNT length or graphene sheet sizes, of a few microns), minimized in order to enable its dispersion in solvent, combined with their random in-plane orientation, significantly limits the mechanical properties of such electrodes. Membranes of CNTs produced by filtration, for example, have a toughness typically $<0.5 \mathrm{~J} / \mathrm{g}$ even after polymer infiltration. ${ }^{25,26}$

A more promising assembly route consists in using longer nanocarbons predominantly aligned parallel to each other into macroscopic fibres. Indeed, macroscopic arrays of CNT fibres have been used not only for supercapacitors, but also as tough electrodes in solar cells, biofuel cells, batteries, energy harvesting devices and other applications. ${ }^{11}$ Reported capacitance values are encouraging, but cover a wide range of 20-100 F/g due to differences in synthesis methods, the presence of a polymer or surfactant, as well as electrochemical conditions of measurement. ${ }^{27-35}$ Most of these materials have been tested as "devices", often as miniature coaxial yarns or intertwined filaments, ${ }^{36-38}$ with only a few examples of planar EDLC with well-defined geometry. ${ }^{39}$ Hence, most of these reports lack data on both the mechanical properties of the electrodes and on their fundamental electrochemical properties, both of which are in fact critical for the envisaged applications of these materials.

This paper sets out as a combined structural, mechanical and electrochemical study of large planar electrodes made up CNT fibres produced continuously on a $\mathrm{km} /$ day scale in our laboratory ${ }^{40}$ and in much larger quantities in semi-industrial settings. ${ }^{41}$ First we present detailed textural measurements, tensile properties and wide-angle $\mathrm{X}$-ray as insight into the network structure of CNT fibres and how it can be easily tailored in our synthetic process. Then we show evidence of quantum capacitance and doping by the electrolyte, illustrating the preservation of the low dimensionality of the building blocks and their high degree of crystallinity. Next we present thorough electrochemical measurements of single electrodes and of symmetric capacitor devices.

\section{Experimental section}

\subsection{Synthesis of CNT fibres}

Carbon nanotubes fibres were synthesized by the direct spinning process from the gas-phase during growth of CNTs by floating catalyst chemical vapour deposition, ${ }^{42}$ using ferrocene as iron catalyst, butanol as carbon source and thiophene as a sulphur catalyst promoter. Thiophene (extra purity $\geq 99 \%$ ) and ferrocene (purity $=98 \%$ ) were obtained from Acros Organics and 2-butanol (purity >99\%) from Sigma Aldrich. Ferrocene was purified by a sublimation/recrystallization process. The reaction was carried out in hydrogen atmosphere at $1250{ }^{\circ} \mathrm{C}$, using precursor feed rates $2 \mathrm{~mL} / \mathrm{h}$ and a fibre winding rate of $20 \mathrm{~m} / \mathrm{min}$, corresponding roughly to a draw ratio of around $6 .{ }^{43}$ The CNT fibres were collected directly on aluminium substrate, used as current collector for some of the electrochemical characterization of the material. Discs of $1 \mathrm{~cm}$ in diameter $\left(0.79 \mathrm{~cm}^{2}\right)$ were cut and used as electrodes for the electrochemical characterization and assembly of the EDLC. Samples were densified with acetone and dried under vacuum at $100^{\circ} \mathrm{C}$ overnight prior to these test.

\subsection{Physicochemical characterization of CNT fibres}

Scanning electron microscopy (SEM) was carried out with a FIB-FEGSEM Helios NanoLab 600i (FEI) at $5 \mathrm{kV}$ and a JEOL JEM $3000 \mathrm{~F}$ TEM at $300 \mathrm{kV}$. Raman spectroscopy was performed using a Renishaw spectrometer with $1 \mathrm{~cm}^{-1}$ spectral resolution, using a $532 \mathrm{~nm}(2.33 \mathrm{eV})$. Laser power was fixed at $10 \%$ power $(3.1 \mathrm{~mW})$ and exposure time to 10 seconds. The shift induced by the presence of IL was observed over a $100 \times 100$ micron area, probed in two-dimensional mapping mode before and after contact with IL. Nitrogen sorption measurements were carried out with $\mathrm{N}_{2}$ at $77 \mathrm{~K}$ after degassing the samples using a Quantachrome Quadrasorb SI porosimeter. Surface area was calculated applying the Brunauer-Emmett-Teller (BET) model to the isotherm data points of the adsorption branch in the relative pressure range $\mathrm{p} / \mathrm{pO}<0.3$. Micropore volume $\left(\mathrm{V}_{\text {micro }}\right)$ was calculated by the $t$-pot method and total pore volume $\left(V_{\text {tot }}\right)$ was obtained from isotherm data at the highest relative pressure achieved $\left(\mathrm{p} / \mathrm{p}_{0}=0.984\right)$. Pore size distribution was determined from the desorption branch of the isotherms applying the Barrett-Joyner-Halendar $(\mathrm{BJH})$ method. Wide angle 2-dimensional X-ray scattering (WAXS) patterns were collected with a Bruker-AXS SMART 1000 single crystal diffractometer using Mo $K \alpha$ radiation and a CCD detector. These samples consisted of multiple parallel CNT fibres produced by winding individual filaments continuously for typically $>10 \mathrm{~min}$, corresponding to $>1000$ filaments. The relative degree of orientation was obtained from the full-width at half-maximum of a Lorentizian fit to the (002) azimuthal profile after subtraction of the isotropic ring originating from 
carbon particulates. These values are substantially higher than those measured on individual CNT fibre filaments due to misalignment between filaments.

\subsection{Characterization of mechanical performance}

Tensile test were carried out on $20 \mathrm{~mm}$ gauge length single filaments of CNT fibres at $0.5 \mathrm{~mm} / \mathrm{min}$ using a Textechno Nominal fibre linear density was determined by weighing a known length of fibre (>50 $\mathrm{m}$ ) and by applying the vibroscopic method.

\subsection{Characterization of electrochemical performance}

Cyclic voltammetries (CV), galvanostatic charge-discharge (CD) tests and electrochemical impedance spectroscopy (EIS) were performed using aBiologic VMP multichannel potentiostaticgalvanostatic system with impedance module. Capacitive behaviour of single electrodes were characterized by $\mathrm{CV}$ in three electrode configuration ("half-cell system") with 1-butyl1-methylpyrrolidinium bis(trifluoromethanesulfonyl)imide (PYR $_{14}$ TFSI) ionic liquid as electrolyte (high purity, $>99.5 \%$ from Solvionic). An array of CNT fibres deposited onto an aluminium disc current collector were used as working electrode. The mass loading of active material was typically around 0.5 $\mathrm{mg} / \mathrm{cm}^{2}$. Silver wire was used as pseudo reference and Pt mesh as counter electrode. Scan rates applied ranged from 5 to 1500 $\mathrm{mV} / \mathrm{s}$. Specific capacitance $\left(C_{s}\right)$ was calculated by integrating the area under the $\mathrm{CV}$ curves.

Measurements of capacitance and electric conductivity of CNT fibres in polarized conditions were performed in 3-electrode configuration. The sample was charged by applying and holding a constant voltage for $10 \mathrm{~min}$ before each impedance measurement was started. The corresponding EIS was determined at that bias voltage at $f=10 \mathrm{mHz}$ and voltage amplitude $=10 \mathrm{mV}$. Impedance experiments were carried out by starting at $0 \mathrm{~V}$ (against $\mathrm{Ag}$ reference) and sequentially increasing the voltage stepping the potential in $\pm 0.1 \mathrm{~V}$. Capacitance values were normalised by BET surface area $\left(C_{A}\right)$. The resistance measurement was performed immediately following the EIS experiment by using a multimeter connected to CNT fibre electrode by two Pt wires after disconnecting the working electrode from the potentiostat. The sequence of impedance and resistance measurements was repeated at different bias voltages from $-1.0 \mathrm{~V}$ to $1.0 \mathrm{~V}$.

Symmetric electric double layer capacitor (EDLC) were built by assembling a Celgard paper between two CNT fibre electrodes of similar weight in a two electrode cell using PYR $_{14}$ TFSI as electrolyte. Electrochemical impedance spectroscopy (EIS) and galvanostatic charge-discharge experiments were used to characterize the full device. The frequency range studied varied from $200 \mathrm{kHz}$ to $10 \mathrm{mHz}$ at bias voltage of $0 \mathrm{~V}$ with a potential amplitude of $10 \mathrm{mV}$. Galvanostatic CD experiments were performed from 0 to $3.5 \mathrm{~V}$ using currents densities ranging from 1 to $50 \mathrm{~mA} / \mathrm{cm}^{2}$. Capacitances of the full device $\left(C_{\text {cell }}\right)$ were obtained from galvanostatic measurements from
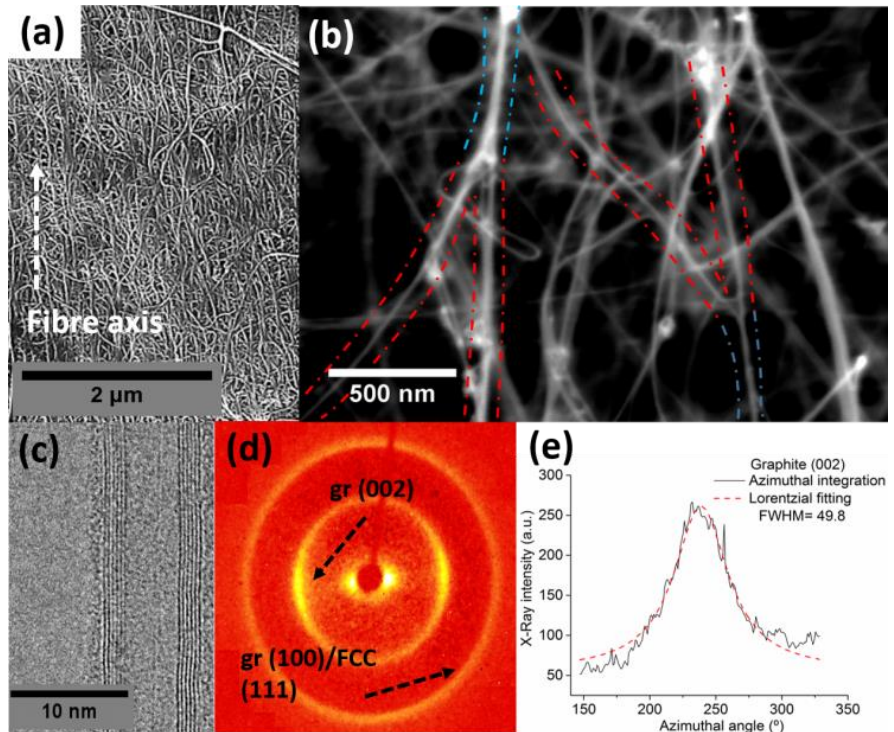

Fig. 1. Electron micrographs and WAXS data showing the microstructure of CNT fibres. (a) The fibres have a network structure of predominantly aligned CNTs forming part of bundles, where they can transfer stress/charge/energy, but also imperfectly packed and giving rise to a large porosity. (b) High magnification SEM micrograph showing CNT bundles branching out. (c) The CNT of this sample are highly graphitised and have few layers. (d) WAXS patterns showing preferential CNT orientation along the fibre axis, with (e) a FWHM of the (002) azimuthal distribution of $50^{\circ}$.

the slope of the discharge curve $\left(C_{c e l l}=l /\right.$ slope $)$. Real energy density $\left(E_{\text {real }}\right)$ and the real power density $\left(P_{\text {real }}\right)$ were calculated by integration of the $C D$ curves according to the following equations:

$$
\begin{aligned}
& E_{\text {real }}=I \int V d t \\
& P_{\text {real }}=E_{\text {real }} / t
\end{aligned}
$$

\section{Results and discussion}

\subsection{CNT fibre structure and textural properties}

Figure 1 presents a combination of electron micrographs of CNT fibres at different magnifications and 2D WAXS data, which together describe the main features that make this material an interesting candidate for tough electrodes. At low magnification (Figure 1a) the sample appears as a dense array of bundles of CNTs with preferential orientation along the fibre axis. At high magnification, the electron micrograph in Figure 1b shows a network structure in which CNTs are interconnected by overlapping over substantial lengths, yet they also branch out and thus form pores. The exceptionally long length of the CNTs in these fibres (up to a $\mathrm{mm}^{44}$ ) implies that they can efficiently transfer stress/energy/charge to adjacent elements even if they are imperfectly packed in other areas. Thus, a large porosity and high-performance mechanical properties can coexist in the same material. On the building block scale, the CNT are highly graphitised and have been appropriately synthesised to have few layers (1 - 5) and small diameter (average inner diameter of $4.7 \mathrm{~nm}$ ). ${ }^{40}$ The degree of orientation can be quantified by WAXS as the full-width at half maximum (FWHM) of the azimuthal profile of the CNT (002) 
reflection, which comes out at $50^{\circ}$ for this sample drawn up to a ratio of 5.7 (Figure 1e). CNT alignment strongly determines bulk mechanical properties, though later in the manuscript we show it to have no noticeable effect on specific surface area. Because the pores in the structure derive from the ensemble of oriented CNTs, the pores themselves are elongated and preferentially oriented parallel to the fibre axis, ${ }^{45}$ as shown by the fibre streak in the SAXS region corresponding to scattering from elements in the $\mathrm{nm}$ range. In addition, a comparison of fibre linear and volumetric density at different draw ratios shows an improvement in packing (Supporting information Fig. 1S).

Further insight into the pore-network structure of CNT fibres is obtained by gas ad/desorption analyses. According to the Brunauer-Deming-Deming-Teller (BDDT) classification, the shape of the isotherm presents mixed features corresponding to both type II and type IV (Figure 2a). Type II is generally found in macroporous materials with a wide distribution of pore sizes but no presence of microporous. Indeed the presence of micropores in CNT fibres was discarded by t-plot determination. At high $\mathrm{P} / \mathrm{P}_{0}>0.8$ the isotherm exhibits a small hysteresis loop, typically present in type IV isotherms, that reveals capillary condensation in big mesopores and macropores. Moreover, the adsorption branch seem to be non-limiting, indicating interparticle adsorption. Figure $2 \mathrm{~b}$ confirms that pore size distribution is broad and includes both large mesopores (> $10 \mathrm{~nm}-50 \mathrm{~nm}$ ) and macropores (> $50 \mathrm{~nm}$ ). The resulting specific surface area $\left(\mathrm{S}_{\mathrm{BET}}\right)$ comes out at $256 \mathrm{~m}^{2} / \mathrm{g}$ and the total pore volume $\left(\mathrm{V}_{\text {tot }}\right)$ at $0.89 \mathrm{~cm}^{3} / \mathrm{g}$. Literature values of $\mathrm{S}_{\mathrm{BET}}$ for CNT fibres are scarce, possibly due to the difficulties to produce the $\sim 1-10 \mathrm{~km}$ of uniform fibre required for a typical BET measurement, but they range from 75 to 500 $\mathrm{m}^{2} / \mathrm{g} \cdot{ }^{37,46-52}$ In summary, isotherm results are in good agreement with electron micrographs and WAXS data and indicate that the high specific surface area of CNT fibres can be attributed to the external surface of aligned long CNTs that through their assembly form slit-shape interparticle pores.

\subsection{Mechanical properties of CNT fibres}

A key feature of the CNT fibre spinning process used is the possibility to tailor the degree of alignment of the CNTs in the fibre by varying the draw ratio of the CNT aerogel during spinning, from a minimum close to $1.5 .{ }^{43} \mathrm{~A}$ higher degree of orientation leads to increases in tensile properties ${ }^{53}$, as shown in the plot of longitudinal fibre modulus as a function of draw ratio, with toughness (energy-to-break) remaining fairly constant (Figure 3a). Although the increase in CNT alignment is
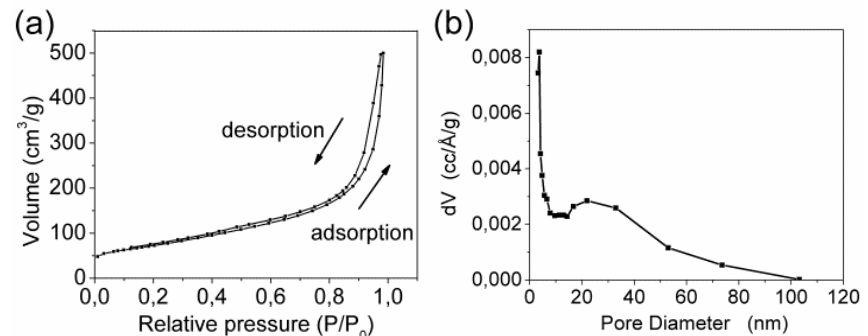

Fig. 2. Textural properties of $C N T$ fibres. (a) $\mathrm{N}_{2}$ adsorption-desorption isotherms and (b) pore size distribution calculated by the BJH method. (a)

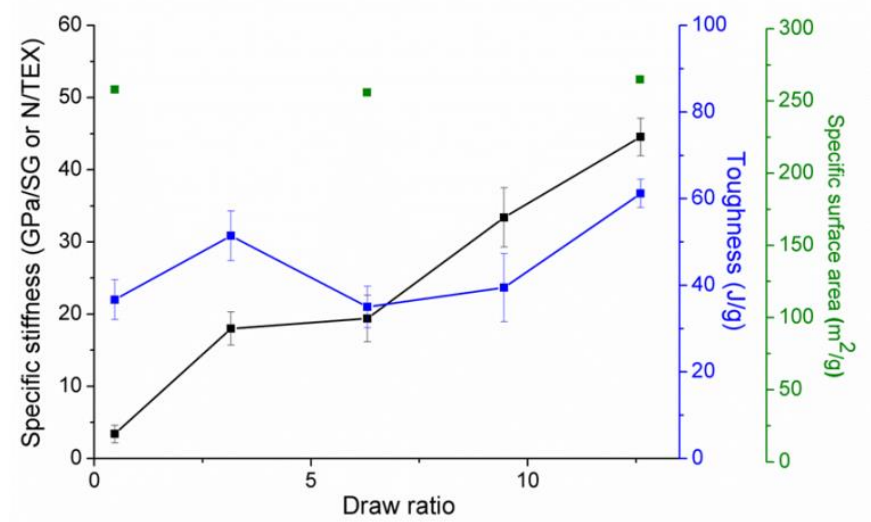

(b)

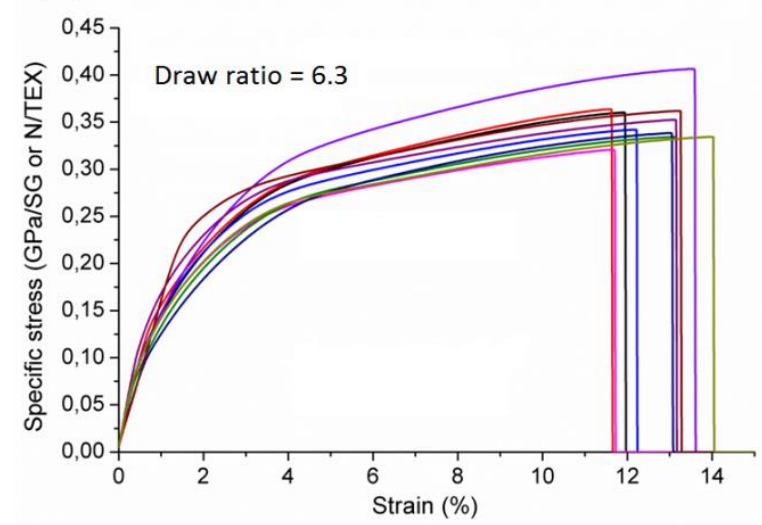

Fig. 3. (a) Dependence of specific stiffness, toughness and specific surface area on draw ratio (winding rate). (b)Strain-stress curve for as-spun CNT fibres, showing mechanical performance of the material.

expected to improve their packing and thus reduce some of the porosity, $\mathrm{S}_{\mathrm{BET}}$ is not substantially affected. This implies that an electrode material with mechanical properties in the highperformance range can be produced without sacrificing its high surface area for energy storage. In this work, we have used fibres with a mid draw ratio (around 6), corresponding to a relatively slow winding rate of $20 \mathrm{~m} / \mathrm{min}$ that facilitated electrode fabrication and sample uniformity. Figure $3 \mathrm{~b}$ shows stress-strain curves for this material. Its specific tensile strength and modulus are $0.35 \mathrm{GPa} / \mathrm{SG}$ and $20 \mathrm{GPa} / \mathrm{SG}$, respectively, similar or above aluminium and steel. Toughness is $35 \mathrm{~J} / \mathrm{g}$, comparable to aramid fibre (Kevlar) and CF. The combination of high toughness and surface area in CNT fibres derives from their long length approaching the $\mathrm{mm}$ scale. The high aspect ratio $\left(10^{5}-10^{6}\right)$ reduces the number of CNT ends and is beneficial for load ${ }^{54}$ and charge transfer, while also allowing for some areas to be imperfectly packed and thus give rise to a substantial porosity. These properties, coupled to a density below $1 \mathrm{~g} / \mathrm{cc}$ and an electrical conductivity around $3.5 \times 10^{5} \mathrm{~S} / \mathrm{m}$ quantitatively demonstrate the potential of CNT fibres as multifunctional active material in electric double layer capacitors (EDLC) and the interest in studying their fundamental electrochemical properties. 
(a)
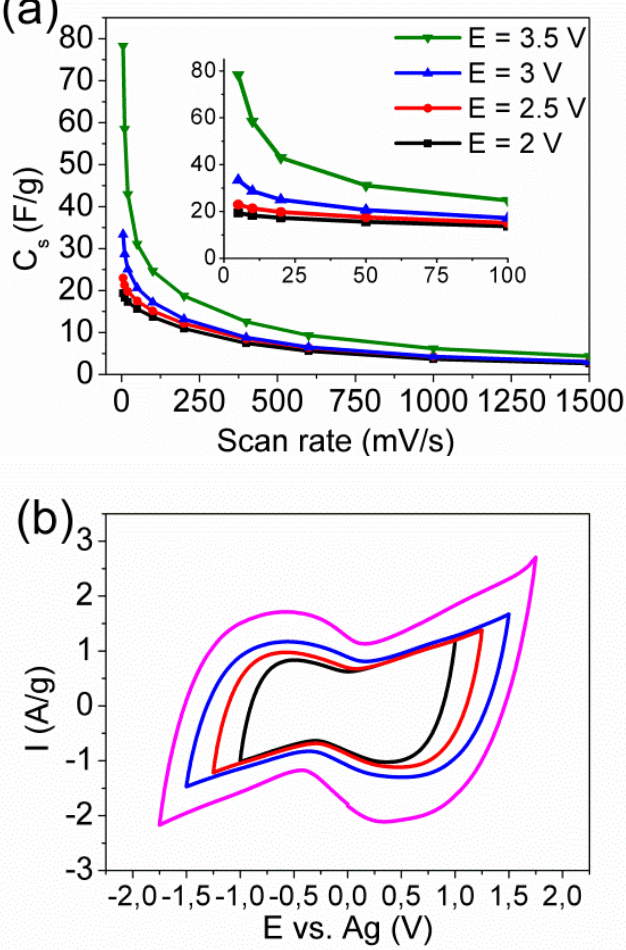

Fig. 4. (a) Specific capacitances $\left(C_{s}\right)$ at different scan rates and voltages limits. (b) CV curves at scan rate of $50 \mathrm{mV} / \mathrm{s}$.

\subsection{Electrochemical properties of CNT fibres and performance of} EDLC

3.3.1 Electrochemical characterization of CNT fibres in 3electrode cell

Planar samples of CNT fibres were characterized by cyclic voltammetry (CV) in 3-electrode electrochemical cell (halfcell). PYR ${ }_{14}$ TFSI ionic liquid was chosen as electrolyte because it combines a high ionic conductivity and wide electrochemical stability window (up to $3.5 \mathrm{~V}$ ). ${ }^{55,56}$ All CV experiments exhibited a coulombic efficiency $\left(\mu=Q^{+} / Q^{-}\right)$higher than $95 \%$, thus considered as within the reversibility criteria. Fig.4a presents the specific capacitance values $\left(C_{s}\right)$ as a function of scan rate and applied voltage. The values of capacitance are very high at low scan rates and high voltage, and then decrease due to slow charging caused by localised $\pi$ states and limitations in electrolyte ion diffusion. ${ }^{57}$ At $3.5 \mathrm{~V}$ for example, $\mathrm{C}_{\mathrm{s}}$ reaches a maximum of $78 \mathrm{~F} / \mathrm{g}$ at $5 \mathrm{mV} / \mathrm{s}$, comparable to values reported for wet-spun CNT fibres (48 and $100 \mathrm{~F} / \mathrm{g}$ for as-spun and annealed CNT fibres, respectively) ${ }^{29}$ and of electrochemically activated CNT fibres (100 F/g). ${ }^{32}$ At lower voltages $2.0 \mathrm{~V}$ to 2.5 $\mathrm{V}$, capacitance remains close to $20-24 \mathrm{~F} / \mathrm{g}$, in line with literature data. ${ }^{28,31,37}$ More interestingly, Figure $4 \mathrm{~b}$ shows that all CV curves are butterfly-shaped, with current changing substantially with applied voltage. Such behaviour is common in quasi-metallic carbons and has been observed in HOPG, 58,59 highly graphitic carbon fibre derived from phenolic resin, 60 some activated carbons, ${ }^{61}$ graphene ${ }^{62}$ and SWCNT. ${ }^{63-65}$ It corresponds to a "chemical" or "quantum" capacitance. ${ }^{66}$ The voltage dependence of capacitance in graphitic systems was initially attributed to a space charge capacitance component corresponding to the spread of charge into the bulk carbon electrode. ${ }^{61}$ In low dimensional systems such as CNTs and graphene, however, it represents a quantum capacitance which follows the density of states (DOS) near the Fermi level, closely revealing features such as the linear dispersion in graphene $^{62}$ and the band gap (if present) and van Hove singularities in CNTs. ${ }^{67}$ In addition, electrochemical characterization of annealed CNT-fiber samples did not show significant difference in capacitive behavior, confirming that impurities do not substantially affect electrochemical properties (Supporting information Fig. 2S).

Figure 5 shows plots of capacitance normalised by surface area $\left(C_{A}\right)$ and relative longitudinal conductivity, as a function of applied potential. The data are directly determined by impedance measurements in 3-electrode cell and referenced to potential at zero charge (pzc). There is good correspondence between the two plots, confirming the quasimetallic nature of the CNT fibre electrodes and the relevance of the DOS for charge screening and transport.

The minimum of $C_{A}$ of $3.2 \mu \mathrm{F} / \mathrm{cm}^{2}$ at $0 \mathrm{pzc}$ is in excellent agreement with values for HOPG 58 and high quality CVD graphene samples. ${ }^{68}$ It confirms the high degree of graphitization of the CNTs produced by the direct spinning process, as indeed is observed by XPS. ${ }^{40}$ The precise lineshape of density of states near the Fermi level of the constituent fewlayer CNTs in the fibres is beyond the scope of this study;

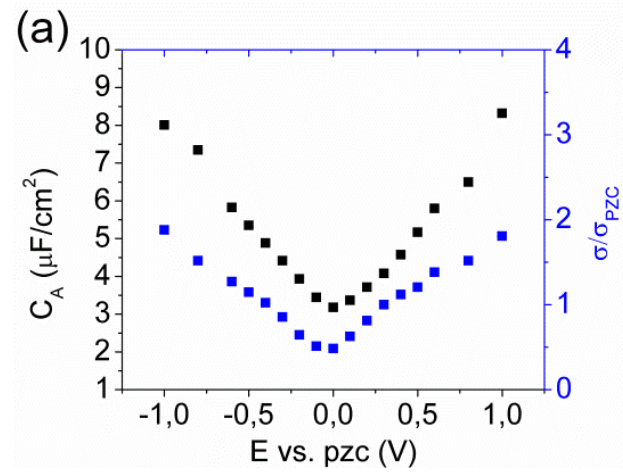

(b)

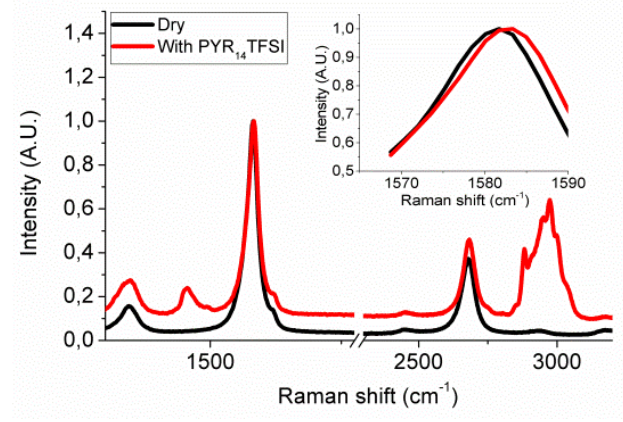

Fig. 5. (a) Area normalized capacitance and normalized conductivity vs. potential at zero charge (pzc) calculated from electrochemical impedance at $10 \mathrm{mHz}$ and different bias voltage. (b) Raman spectra of a CNT fibre sample electrode showing upshifts in the $2 \mathrm{D}$ and $\mathrm{G}$ bands as a consequence of hole doping after impregnation with IL. 
however, we note that assuming a linear dispersion relation in the range $(0- \pm 1 \mathrm{~V})$ the left and right slopes of $\mathrm{C}_{\mathrm{A}} / \mathrm{pzC}$ are 5 $\left(\mu \mathrm{F} / \mathrm{cm}^{2}\right) / \mathrm{V}$, comparable to 3-5 layer high-quality graphene with aqueous electrolyte $\left(2.5-7\left(\mu \mathrm{F} / \mathrm{cm}^{2}\right) / \mathrm{V}\right) .{ }^{68}$ We further note that the pzc is shifted relative to the Ag reference electrode by about $0.35 \mathrm{~V}$, which is probably partly a consequence of carrier doping by the ionic liquid. Raman spectroscopy measurements before and after contact with IL show an upshift of the 2D and $\mathrm{G}$ bands of $5 \mathrm{~cm}^{-1}(2677.5 \pm 0.5$ to $2685.5 \pm 0.1)$ and $2 \mathrm{~cm}^{-1}$, (1579.6 \pm .33 to $1581.6 \pm 0.11$ ) respectively, (Figure 5b). Raman measurements confirm that indeed the IL acts as a p-dopant providing roughly one hole per $150 \mathrm{C}$-atoms at OV (assuming $275 \mathrm{~cm}^{-1}$ per hole per C-atom). ${ }^{69,70}$ Our choice of IL, PYR 14 TFSI, is known to interact strongly with CNTs ${ }^{71}$ and it is not unlikely that further contributions to capacitance arise from correlations between the $\pi$ electron cloud and the ions in the IL Helmohltz layer. ${ }^{68}$ The results above highlight the fact that even bulk samples of CNT fibre electrodes preserve the low dimensionality of their nanobuilding blocks. While control of the type of CNTs could have at first seemed only to affect textural properties of electrodes, the electronic structure of
CNTs and its coupling to the electrolyte at a molecular level are clearly relevant in these systems.

\subsubsection{Electrochemical characterization of planar EDLC}

EIS measurements on CNT fibre-based ELDC give a Nyquist plot, presented in Figure 6a, shows a vertical straight line at low frequencies typical of capacitive behaviour. Due to high electrical conductivity of the fibres and presence of accessible meso and macropores, equivalent series resistance (ESR) is only around $30 \mathrm{Ohm}$, half of that in similar EDLC prepared with activated carbon electrodes. ${ }^{72}$ Fig. $6 \mathrm{~b}$ shows the chargedischarge voltage profile of CNT fibre-based EDLC from $0 \mathrm{~V}$ to $3.5 \mathrm{~V}$ at $5 \mathrm{~mA} / \mathrm{cm}^{2}$. As opposed to a conventional EDLC in which the slope of the voltage profile is constant (and consequently so is capacitance), in CNT fibre electrodes the dependence of capacitance on bias voltage (Figure 5a) manifests as bulging of the $C D$ profiles. We have estimated the contribution of quantum capacitance to the discharge curve by plotting a discharge line with the slope at pzc, which is equivalent to assuming that the capacitance at pzc is constant (a)

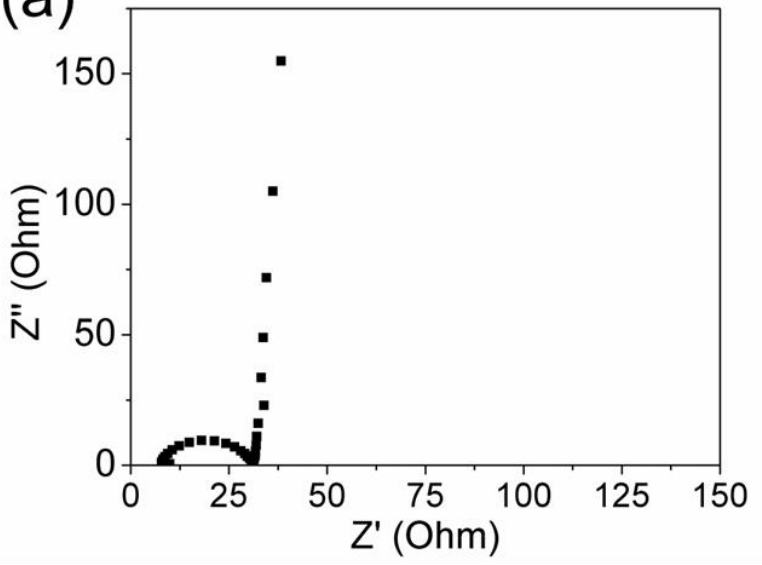

(b)

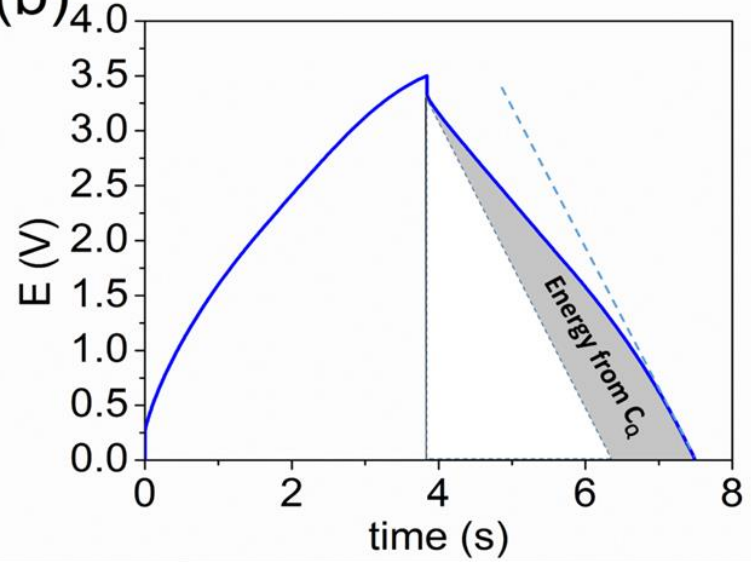

(c)

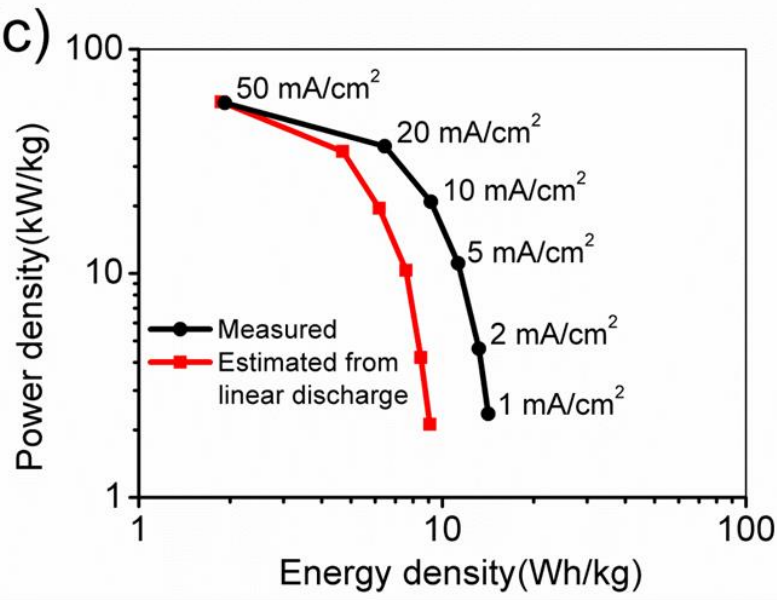

(d)

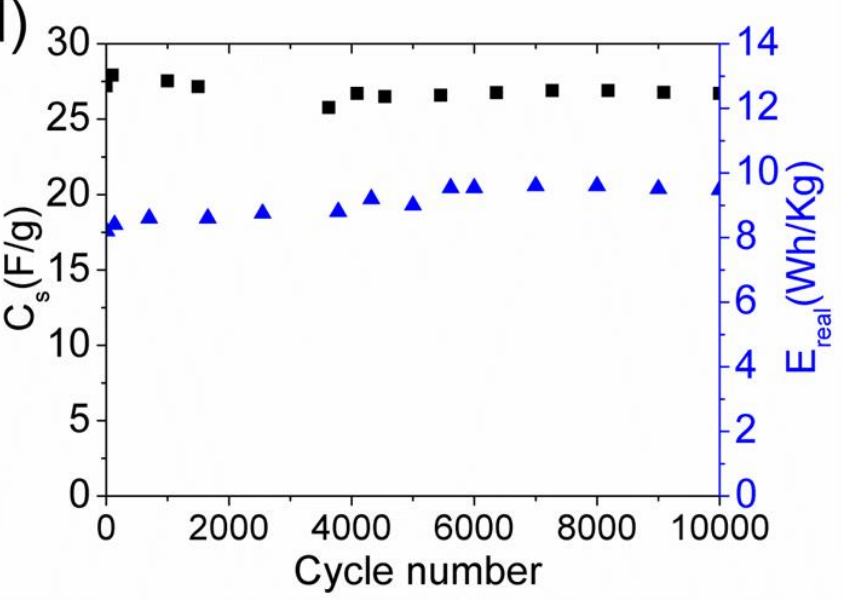

Fig. 6. Electrochemical characterization of CNT fibre-based EDLC assembled with PYR ${ }_{14} T F S I$ ionic liquid electrolyte and two planar CNT fibre electrodes. (a) Nyquist plot (b) Galvanostatic charge-discharge (CD) profile at $3.5 \mathrm{~V}$ and $5 \mathrm{~mA} / \mathrm{cm}^{2}$ demonstrating quantum capacitance contribution to the total energy of the SC. (c) Ragone plot (obtained from measured CD and estimated from theoretical ideal EDLC behaviour). (e) Cycling stability test of the EDLC over 10000 cycles at $5 \mathrm{~mA} / \mathrm{cm}^{2}$. 
(Figure $6 \mathrm{~b}$ ). The results shows that the quantum capacitance $\left(C_{Q}\right)$ of the electrodes produces substantial increases in the real energy densities of the device, obtained by the integration of the $C D$ curves. Figure $6 c$ presents a Ragone plot showing the comparison between real energy and power densities, and those assuming a linear CD profile. The enhancement in device performance is largely a product of the fibre spinning method enabling the synthesis of electrodes that preserve the electronic features of their low dimensional building blocks. The other component of the device, the IL, is in an ideal match for the CNT system. Its stability window up to $3.5 \mathrm{~V}$ implies that large energy and power densities can be attained. But because of the dependence of capacitance on bias voltage, energy and power density are expected to scale with as $\mathrm{V}^{\mathrm{X}}$, where $\mathrm{X}$ is $\approx 3$, as opposed to conventional EDLC with $X=2$. Thus, the high electrochemical stability of the PYR ${ }_{14} T F S I$, compared for example to an aqueous electrolyte, results in energy density values approaching the pseudocapacitor and battery range and to the best of our knowledge, the highest reported for CNT fibre-based active materials. Maximun energy and power values were as high as $14 \mathrm{Wh} / \mathrm{kg}$ at $1 \mathrm{~mA} / \mathrm{cm}^{2}$ and $58 \mathrm{~kW} / \mathrm{kg}$ at $50 \mathrm{~mA} / \mathrm{cm}^{2}$, respectively.

The cycling stability of the device was also measured, by performing 10000 charge-discharge cycles at an intermediate current density of $5 \mathrm{~mA} / \mathrm{cm}^{2}$. Presented in Figure $6 \mathrm{~d}$ as changes in specific capacitance $\left(C_{s}\right)$ and real energy density ( $\left.E_{\text {real }}\right)$ against number of cycles, the data show very good cyclability. The capacitance retention was found to be higher than $93 \%$ while energy density increased in $14 \%$ during first 6000 cycles and then remained constant for the next 4000 cycles.

As a figure of merit of combined electrochemical and mechanical performance, in Figure 7 we present a log-log plot of specific capacitance versus toughness for CNT fibres, membranes based on nanocarbons, and commercial CF. The top right corner, representing optimum exploitation of both properties, is clearly dominated by CNT fibres due to two key

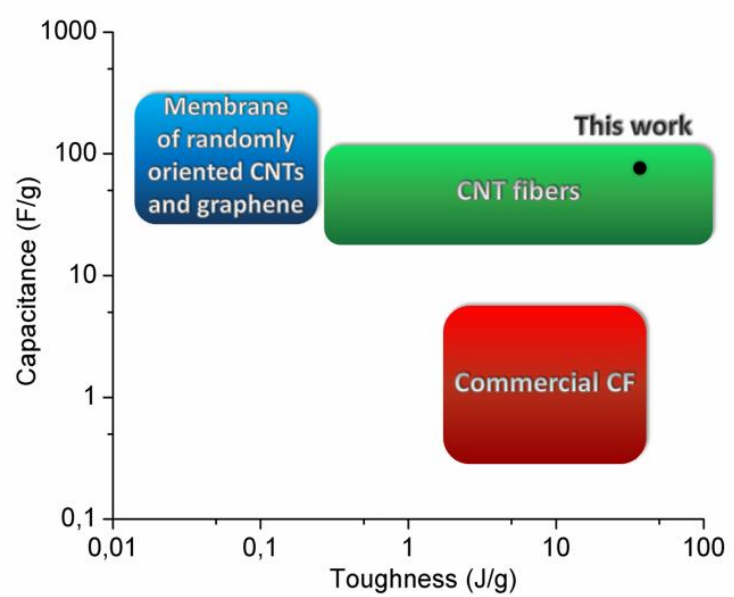

Fig. 7. The plot of specific capacitance against toughness for different carbon-based materials. $25,29,31,33,48,73-75$ attributes of their structure, namely the preferential orientation of the CNTs and their exceptionally long length.

\section{Conclusions}

CNT fibres were synthesized by the direct spinning process from the gas-phase during growth of CNTs by floating catalyst CVD. The degree of alignment of CNT along the axis of the fibre and consequently the mechanical properties of the fibres, could be tailored by varying the draw ratio of the CNT aerogel during spinning. Interestingly, the specific surface area of the obtained materials remained constant at values around 250 $\mathrm{m}^{2} / \mathrm{g}$ in spite of the possible improved packing of elements in the fibre at higher draw ratios. CNT fibres with specific tensile strength and modulus of $0.35 \mathrm{GPa} / \mathrm{SG}$ and $20 \mathrm{GPa} / \mathrm{SG}$, (similar or above aluminium and steel) and toughness of $35 \mathrm{~J} / \mathrm{g}$ (comparable to Kevlar and CF) exhibited specific capacitances of $78 \mathrm{~F} / \mathrm{g}$, quite close to the highest values reported in literature for CNT fibres and close to activated carbons or CNT or graphene papers. Moreover, the dependence of areanormalized capacitance and electrical conductivity on electrode potential was demonstrated with $\mathrm{C}_{\mathrm{A}}$ values ranging from $3.2 \mu \mathrm{F} / \mathrm{cm}^{2}$ at potential of zero charge (pzc) to $8 \mu \mathrm{F} / \mathrm{cm}^{2}$ at $-1.0 \mathrm{~V}$ (vs. pzc). These values are similar to those for HOPG and high quality CVD graphene confirming the high degree of graphitization of CNT and their quasimetallic nature. CNT fibrebased EDLC showed excellent cycling stability over 10000 cycles at $3.5 \mathrm{~V}$, and values of energy density as high as 14 $\mathrm{Wh} / \mathrm{kg}$ and power density reaching $58 \mathrm{~kW} / \mathrm{kg}$, the highest values reported for CNT fibre materials so far, to the best of our knowledge.

In addition to reinforcing the potential of these materials as tough electrodes for energy storage, this work demonstrates that the bottom-up assembly of CNT fibres does indeed result in macroscopic devices that retain features associated with the low dimensionality of their building blocks. The large contribution of quantum capacitance to the power and energy density of devices point to the engineering of the band structure of the CNTs, as well as their interaction with dopants, as examples of possible strategies to further enhance the electrochemical properties of these devices.

\section{Acknowledgements}

Generous financial support is acknowledged from the European Union Seventh Framework Program under grant agreements 310184 (CARINHYPH project) and 322129 (Marie Curie Action MUFIN), the Spanish Ministry of Innovation and Competiveness under grants MAT2012-37552-C03-02 and ENE2012-31516 and "Juan de la Cierva" and "Ramón y Cajal" fellowships, and the Madrid regional government under grant S2013/MIT-3007 (MAD2D project).

\section{References}



2015, 137, 511-536.

E. Karden, S. Ploumen, B. Fricke, T. Miller and K. Snyder, J. Power Sources, 2007, 168, 2-11.

N. Shirshova, H. Qian, M. S. P. Shaffer, J. H. G. Steinke, E. S. Greenhalgh, P. T. Curtis, A. Kucernak and A. Bismarck, Compos. Part A Appl. Sci. Manuf., 2013, 46, 96-107.

H. Qian, H. Diao, N. Shirshova, E. S. Greenhalgh, J. G. H. Steinke, M. S. P. Shaffer and A. Bismarck, J. Colloid Interface Sci., 2013, 395, 241-248.

N. Shirshova, H. Qian, M. Houllé, J. H. G. Steinke, A. R. J. Kucernak, Q. P. V. Fontana, E. S. Greenhalgh, A. Bismarck and M. S. P. Shaffer, Faraday Discuss., 2014, 44, 81-103.

H. Qian, A. R. Kucernak, E. S. Greenhalgh, A. Bismarck and M. S. P. Shaffer, ACS Appl. Mater. Interfaces, 2013, 5, 6113.

E. Greenhalgh, J. Ankersen, L. Asp, A. Bismarck, Q. Fontana, M. Houlle, G. Kalinka, A. Kucernak, M. Mistry, S. Nguyen, H. Qian, M. Shaffer, N. Shirshova, J. Steinke and M. Wienrich, J. Compos. Mater., 2014, 49, 1823-1834.
Y. J. Kang, S.-J. Chun, S. S.-Y. Lee, B.-Y. Kim, J. H. Kim, H. Chung and W. Kim, ACS Nano, 2012, 6, 6400-6.

L.-F. Chen, Z.-H. Huang, H.-W. Liang, W.-T. Yao, Z.-Y. Yu and S.-H. Yu, Energy Environ. Sci., 2013, 6, 3331.

M. F. El-Kady, V. Strong, S. Dubin and R. B. Kaner, Science, 2012, 335, 1326-30.

M. Kaempgen, C. K. Chan, J. Ma, Y. Cui and G. Gruner, Nano Lett., 2009, 9, 1872-6.

C. Zhou and J. Liu, Nanotechnology, 2014, 25, 035402.

M. Notarianni, J. Liu, F. Mirri, M. Pasquali and N. Motta, Nanotechnology, 2014, 25, 435405.

J. Liu, F. Mirri, M. Notarianni, M. Pasquali and N. Motta, J. Power Sources, 2014, 274, 823-830.

J. N. Coleman, W. J. Blau, A. B. Dalton, E. Muñoz, S. Collins, B. G. Kim, J. Razal, M. Selvidge, G. Vieiro and R. H. Baughman, Appl. Phys. Lett., 2003, 82, 1682.

N. A. Kumar, I.-Y. Jeon, G.-J. Sohn, R. Jain, S. Kumar and J.B. Baek, ACS Nano, 2011, 5, 2324-31.

S. R. Shin, C. K. Lee, I. S. So, J. H. Jeon, T. M. Kang, C. W. Kee, S. J. Kim, G. M. Spinks, G. G. Wallace and S. J. Kim, Adv. Mater., 2008, 20, 466-470.

A. B. Dalton, S. Collins, E. Muñoz, J. M. Razal, V. H. Ebron, J. P. Ferraris, J. N. Coleman, B. G. Kim and R. H. Baughman, Nature, 2003, 423, 703.

M. E. Kozlov, R. C. Capps, W. M. Sampson, H. Von Ebron, J. P. Ferraris, R. H. Baughman and V. H. Ebron, Adv. Mater., 2005, 17, 614-617.

T. Mirfakhrai, J. Oh, M. Kozlov, E. C. W. Fok, M. Zhang, S. Fang, R. H. Baughman and J. D. W. Madden, Smart Mater. Struct., 2007, 16, S243-S249.

T. Mirfakhrai, J. Oh, M. Kozlov, S. Fang, M. Zhang, R. H. Baughman and J. D. W. Madden, J. Electrochem. Soc., 2009, 156, K97.

G. Sun, J. Zhou, F. Yu, Y. Zhang, J. H. L. Pang and L. Zheng, J. Solid State Electrochem., 2011, 16, 1775-1780.

L. Viry, C. Mercader, P. Miaudet, C. Zakri, A. Derré, A. Kuhn, M. Maugey and P. Poulin, J. Mater. Chem., 2010, 20, 3487.

C. Lynam, S. E. Moulton and G. G. Wallace, Adv. Mater., 2007, 19, 1244-1248. 
35 Y. Feng, F. Ningning and D. Guixiang, Int. J. Electrochem. Sci., 2012, 7, 12432-12439.

X. Chen, L. Qiu, J. Ren, G. Guan, H. Lin, Z. Zhang, P. Chen, Y. Wang and H. Peng, Adv. Mater., 2013, 25, 6436-41.

J. Smithyman and R. Liang, Mater. Sci. Eng. B, 2014, 184, 34-43.

J. Ren, L. Li, C. Chen, X. Chen, Z. Cai, L. Qiu, Y. Wang, X. Zhu and H. Peng, Adv. Mater., 2013, 25, 1155-9, 1224

J. Benson, I. Kovalenko, S. Boukhalfa, D. Lashmore, M

Sanghadasa and G. Yushin, Adv. Mater., 2013, 25, 6625-32.

V. Reguero, B. Alemán, B. Mas and J. J. Vilatela, Chem. Mater., 2014, 26, 3550-3557.

M. W. Schauer and M. A. White, MRS Proc., 2015, 1752.

Y.-L. Li, I. A. Kinloch and A. H. Windle, Science, 2004, 304, 276-8.

B. Alemán, V. Reguero, B. Mas and J. J. Vilatela, ACS Nano, 2015, 9, 7392-8.

M. Motta, A. Moisala, I. A. Kinloch and A. H. Windle, Adv. Mater., 2007, 19, 3721-3726.

R. J. Davies, C. Riekel, K. K. Koziol, J. J. Vilatela and A. H. Windle, J. Appl. Crystallogr., 2009, 42, 1122-1128.

J. Qiu, J. Terrones, J. J. Vilatela, M. E. Vickers, J. A. Elliott and A. H. Windle, ACS Nano, 2013, 7, 8412-22.

A. V. Neimark, S. Ruetsch, K. G. Kornev, P. I. Ravikovitch, P. Poulin, S. Badaire and M. Maugey, Nano Lett., 2003, 3, 419-423.

X.-H. Zhong, Y.-L. Li, Y.-K. Liu, X.-H. Qiao, Y. Feng, J. Liang, J. Jin, L. Zhu, F. Hou and J.-Y. Li, Adv. Mater., 2010, 22, 692-6.

A. D. Leonard, J. L. Hudson, H. Fan, R. Booker, L. J. Simpson, K. J. O'Neill, P. a Parilla, M. J. Heben, M. Pasquali, C. Kittrell and J. M. Tour, J. Am. Chem. Soc., 2009, 131, 723-8.

J. Qiu, J. Terrones, J. J. Vilatela, M. E. Vickers, J. A. Elliott and A. H. Windle, 2013.

J. Terrones, A. H. Windle and J. a Elliott, Sci. Technol. Adv. Mater., 2014, 15, 055008.

J. J. Vilatela, R. Khare and A. H. Windle, Carbon N. Y., 2012, 50, 1227-1234.
K. Koziol, J. Vilatela, A. Moisala, M. Motta, P. Cunniff, M. Sennett and A. Windle, Science (80-. )., 2007, 318, 18921895.

J. J. Vilatela, J. A. Elliott and A. H. Windle, ACS Nano, 2011, 5, 1921-7.

N. Fechler, G. A. Tiruye, R. Marcilla and M. Antonietti, RSC Adv., 2014, 4, 26981.

M. Lazzari, M. Mastragostino and F. Soavi, Electrochem. commun., 2007, 9, 1567-1572.

Y. Oren and A. Soffer, J. Electroanal. Chem. Interfacial Electrochem., 1985, 186, 63-77.

J.-P. Randin and E. Yeager, J. Electrochem. Soc., 1971, 118, 711.

J.-P. Randin and E. Yeager, J. Electroanal. Chem. Interfacial Electrochem., 1972, 36, 257-276.

I. Tanahashi, J. Electrochem. Soc., 1990, 137, 3052.

M. Hahn, M. Baertschi, O. Barbieri, J.-C. Sauter, R. Kötz and R. Gallay, Electrochem. Solid-State Lett., 2004, 7, A33.

J. Xia, F. Chen, J. Li and N. Tao, Nat. Nanotechnol., 2009, 4, 505-509.

T. Osamu, F. D. N., H. Kenji and H. Hiroaki, Carbon Lett., 2009, 10, 90-93.

O. Kimizuka, O. Tanaike, J. Yamashita, T. Hiraoka, D. N. Futaba, K. Hata, K. Machida, S. Suematsu, K. Tamamitsu, S. Saeki, Y. Yamada and H. Hatori, Carbon N. Y., 2008, 46, 1999-2001.

A. Al-Zubaidi, T. Inoue, T. Matsushita, Y. Ishii, T. Hashimoto and S. Kawasaki, J. Phys. Chem. C, 2012, 116, 7681-7686.

J. Bisquert, Nanostructured energy devices: equilibrium concepts and kinetics, CRC Press, Boca Raton, Fla., 2015.

S. Ilani, L. A. K. Donev, M. Kindermann and P. L. McEuen, Nat. Phys., 2006, 2, 687-691.

H. Ji, X. Zhao, Z. Qiao, J. Jung, Y. Zhu, Y. Lu, L. L. Zhang, A. H. MacDonald and R. S. Ruoff, Nat. Commun., 2014, 5.

L. Kavan, P. Rapta, L. Dunsch, M. J. Bronikowski, P. Willis and R. E. Smalley, J. Phys. Chem. B, 2001, 105, 1076410771.

G. U. Sumanasekera, J. L. Allen, S. L. Fang, A. L. Loper, A. M. Rao and P. C. Eklund, J. Phys. Chem. B, 1999, 103, 42924297. 
M. M. Jaramillo, A. Mendoza, S. Vaquero, M. Anderson, J. Palma and R. Marcilla, RSC Adv., 2012, 2, 8439.

J. F. Snyder, E. L. Wong and C. W. Hubbard, J. Electrochem. Soc., 2009, 156, A215.

Q. Cheng, J. Tang, J. Ma, H. Zhang, N. Shinya and L.-C. Qin, Phys. Chem. Chem. Phys., 2011, 13, 17615-24.

75 D. a Dikin, S. Stankovich, E. J. Zimney, R. D. Piner, G. H. B. Dommett, G. Evmenenko, S. T. Nguyen and R. S. Ruoff, Nature, 2007, 448, 457-60. 